\title{
Predicting Deformation of Parts from HP Printers due to Sintering with Modeling and Simulation
}

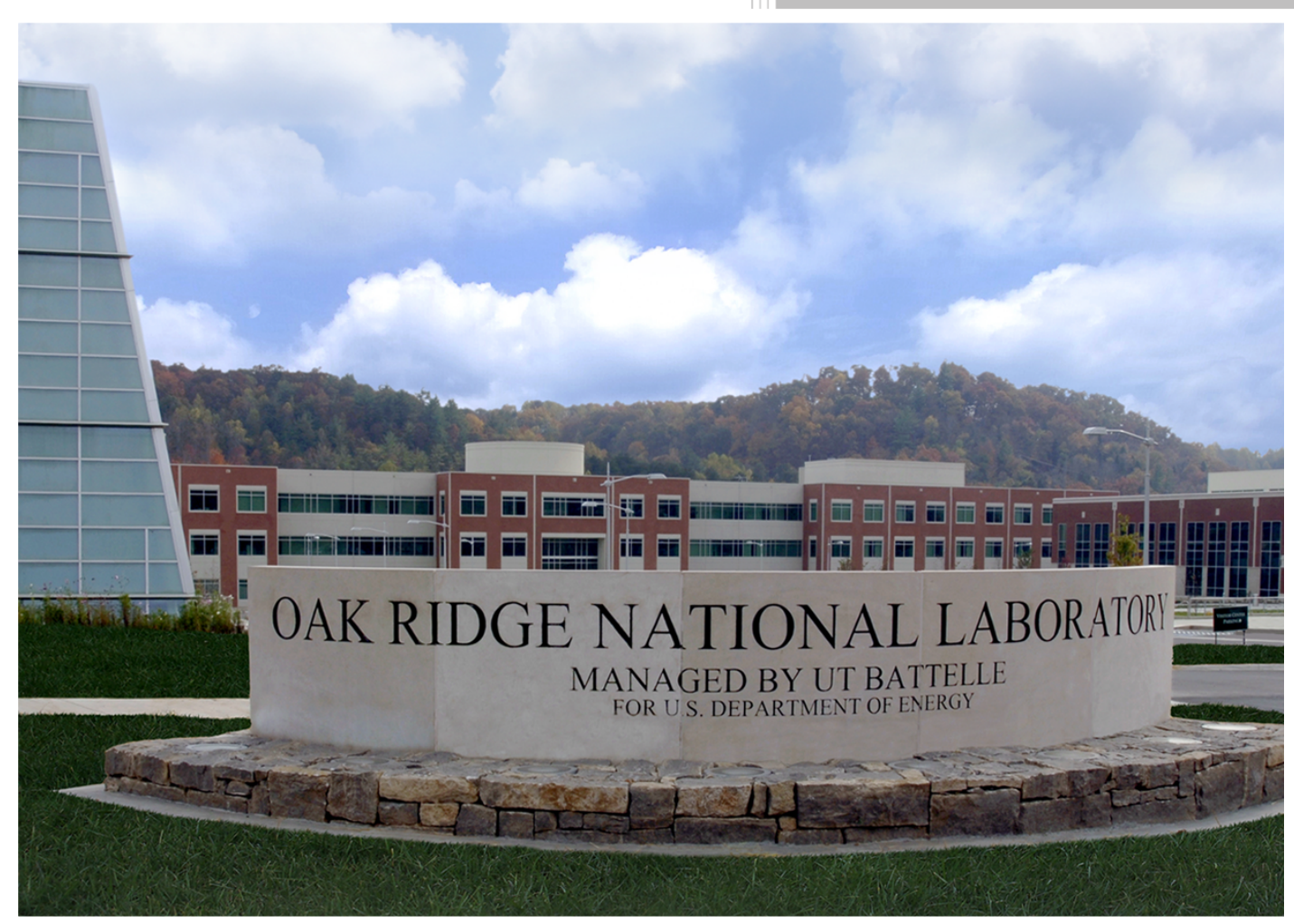

\section{Approved for Public Release. Distribution is Unlimited.}




\section{DOCUMENT AVAILABILITY}

Reports produced after January 1, 1996, are generally available free via US Department of Energy (DOE) SciTech Connect.

Website http://www.osti.gov/scitech/

Reports produced before January 1, 1996, may be purchased by members of the public from the following source:

National Technical Information Service

5285 Port Royal Road

Springfield, VA 22161

Telephone 703-605-6000 (1-800-553-6847)

TDD 703-487-4639

Fax 703-605-6900

E-mail info@ntis.gov

Website http://www.ntis.gov/help/ordermethods.aspx

Reports are available to DOE employees, DOE contractors, Energy Technology Data Exchange representatives, and International Nuclear Information System representatives from the following source:

Office of Scientific and Technical Information

PO Box 62

Oak Ridge, TN 37831

Telephone 865-576-8401

Fax 865-576-5728

E-mail reports@osti.gov

Website http://www.osti.gov/contact.html

This report was prepared as an account of work sponsored by an agency of the United States Government. Neither the United States Government nor any agency thereof, nor any of their employees, makes any warranty, express or implied, or assumes any legal liability or responsibility for the accuracy, completeness, or usefulness of any information, apparatus, product, or process disclosed, or represents that its use would not infringe privately owned rights. Reference herein to any specific commercial product, process, or service by trade name, trademark, manufacturer, or otherwise, does not necessarily constitute or imply its endorsement, recommendation, or favoring by the United States Government or any agency thereof. The views and opinions of authors expressed herein do not necessarily state or reflect those of the United States Government or any agency thereof. 
ORNL/TM-2020/1885

CRADA/NFE-18-07363

Energy and Transportation Science Division
Advanced Manufacturing Office

\title{
Predicting Deformation of Parts From HP Printers due to Sintering With Modeling and
} Simulation

Jay Jay Billings

Date Published: January 2021

\author{
Prepared by \\ OAK RIDGE NATIONAL LABORATORY \\ Oak Ridge, Tennessee 37831-6283 \\ managed by \\ UT-BATTELLE, LLC \\ for the \\ US DEPARTMENT OF ENERGY \\ under contract DE-AC05-00OR22725
}

Approved for public release 


\section{ABSTRACT}

This work proposes to leverage Oak Ridge National Laboratory's (ORNL) sintering simulation software developed at the Manufacturing Demonstration Facility to 1) investigate the deformation of sintered parts and 2) to develop fast surrogate-based optimization methods for HP Inc. This includes the development of ORNL's software on HP systems, integration and testing with HP part geometries and material properties, the development of surrogate models based on the results of the simulation, and modifications to the software based on feedback from HP. The expected impacts of this work are a drastic reduction in print costs, an increase in printer throughput, and the identification of novel, possibly exotic materials for 3D printing. This work will also decrease the time to market for HP's print technology by decreasing the amount of resources and type dedicated to physical testing.

\section{BACKGROUND}

The strength, durability, and size of 3D printed parts are greatly inhibited by the inability to postprocess these parts with standard industrial engineering techniques, such as sintering in a furnace, without causing catastrophic deformations. The deformations often include large fractures and shrinking, often up to $50 \%$ of the original volume. The current process for applying these post-processing techniques is very costly and repetitive, requiring engineers creating multiple parts with small geometric deviations from the ideal geometry and manually sintering these parts until a "good enough" candidate is found that warps into the ideal geometry. This presents the opportunity to examine the deformation instead with fast computational models to 1) understand the effects of sintering across geometries and material types, and 2) to develop surrogate models and optimization schemes to computationally derive the initial geometry that deforms into the ideal geometry after sintering.

However, while sintering is becoming an essential piece of additive manufacturing technology, many sintering models to date have very constrained conditions that prohibit them from being widely used in industry and academia. ORNL has been developing a new sintering simulator, named Kelvin, based on the Material Point Method that can handle binder jet post processing in a much more effective manner. HP Inc is interested in being able to effectively model the binder jet post processing step and is entering into this partnership with ORNL to expedite the progress of model development.

The development of a working sintering model based on the Material Point Method is the primary goal of this partnership. In addition to model development, advice on setting up the model correctly by identifying which inputs are required and ways to get these inputs. 


\section{PROJECT PLAN}

The overall objective of this project is to develop an optimized sintering simulation toolchain to simulate deformation in HP's 3D printing process using ORNL's Kelvin software for simulating sintering. Two tasks are proposed to achieve this objective: 1) Deploy and optimize ORNL's open-source deformation prediction software for HP and 2) Use the deformation prediction software to generate a shape-compensated geometry for printing to ensure the part prints asdesigned.

\section{Task 1: Deploy and optimize ORNL's open-source software for HP}

This includes on-going development of a working sintering model based on the Material Point Method (MPM) and joint development of requirements for generating and measuring accurate material and geometric properties. Task I will see ORNL and HP start with a test geometry provided by ORNL and simulations performed with both open and proprietary material properties under ideal sintering conditions for both. This analysis will be used to optimize the simulation tool to run in a timeframe appropriate for the problem size and method. Joint investigation of material properties and other conditions will include enumeration of all information required by the simulator, the identification of necessary tests for HP to perform on its parts, and the exact workflow required to execute simulations in ORNL's software.

\section{Task 2: Develop and deploy a predictor-corrector model}

This leverages the predictive model described in Task I and leverages it to create a predictorcorrector model that will be used as part of the printing process. This process will work as follows.

Kelvin will be used as described in Task 1 to distort the input geometry in a simulation of creep and sintering effects. The output will then be used to create a parameterized model of the distorted geometry with a method similar to the Reduced Basis Method. The parameterized model will then be used to create a fast-running "surrogate" model that can be used in place of Kelvin. One or more optimization codes will be used to optimize the input geometry using the physics-based surrogate model. This post processing loop may be run iteratively to reduce the delta between the size and shape of the designed part and the size and shape of the printed and post-processed shape-compensated part and will allow users to target specific areas that may be highly deformed.

\section{STATUS}

Work on this project unexpectedly ended early in April 2019 after the ORNL PI was moved to a different position within ORNL and the HP PI was pulled onto other projects at that company. Until that time, this project accomplished the following tasks:

1.) Kelvin, ORNL's sintering simulation software, was released open source to GitHub (https://github.com/ornl/kelvin) and made available to HP.

2.) Kelvin was compiled and tested on HP computing hardware.

3.) Extensions were made to Kelvin to allow for the implementation of custom/proprietary plugins to compute constitutive properties. 
The following image shows the geometry of a tapered cooling cool converted from a finite element mesh to a collection of particles for simulation in Kelvin.

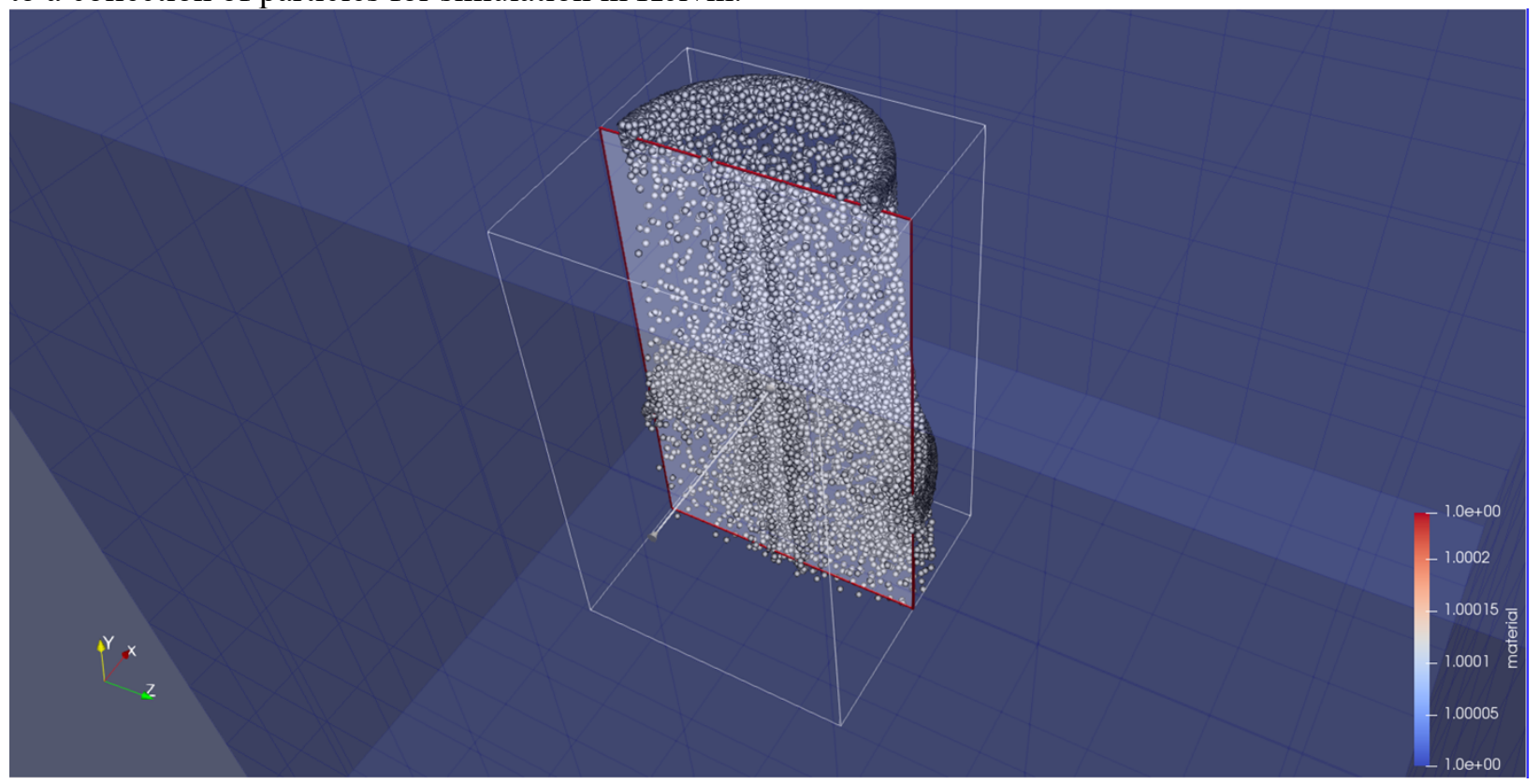

